Egyptian Journal of Aquatic Biology \& Fisheries

Zoology Department, Faculty of Science,

Ain Shams University, Cairo, Egypt.

ISSN 1110 - 6131

Vol. 22(4): 181- 193 (2018)

ejabf.journals.ekb.eg

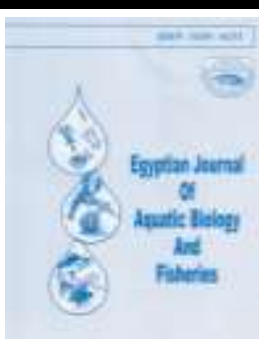

\title{
Fenton Oxidation and Fungal Remediation of Different Pollutants from
} Kitchener Drain, Egypt.

\section{Ahmed S. Gebreil ${ }^{1}$; Muhammad A. El-Alfy ${ }^{2 *}$; Yasser A. El-Amier ${ }^{1}$; Eman H. Abd El-Salam ${ }^{1}$}

1- Botany Department, Faculty of Science, Mansoura University, Mansoura, Egypt

2- Marine Pollution Department, National Institute of Oceanography \& Fisheries, Egypt.

*Corresponding Author: muhammad.elalfy@yahoo.com

\section{ARTICLE INFO Article History: \\ Received: Aug. 9, 2018 \\ Accepted: Sept. 8, 2018 \\ Available online: Sept.15, 2018}

\section{Keywords: \\ Wastewater \\ Kitchener Drain \\ Remediation \\ Fenton \\ Fungi \\ Batch Mode}

\begin{abstract}
Wastewater from Kitchener drain cause many effects not only on the surrounding environment but when being discharged into the Mediterranean Sea water. Using different remediation processes for heavy metals removal has important role in purification of different types of wastewaters aid in recycling process. This work is aimed to use Fenton as chemical remediation process for reduction of organic pollutants and to screen the efficiency of the fungal isolates in heavy metal removal process by generation of an immobilized fungal consortium. Parameters affecting the Fenton process as $\mathrm{pH}$, dosages of Fenton reagents and temperature were taken into considerations in this research. Results showed that the optimum conditions to have high removal of organic matter from wastewater sample at the experiment were at $\mathrm{FeSO}_{4}(0.4 \mathrm{gm})$, hydrogen peroxide $\mathrm{H}_{2} \mathrm{O}_{2}(15 \%)$, at acidic medium $(\mathrm{pH}=2)$ and temperature of about $40^{\circ} \mathrm{C}$. It showed high removal of chemical oxygen demand COD concentration from sample with 80 to $95 \%$ removal. On the other experiment, a mixture of fungal spores was used to remove Chromium, Cadmium and Nickel ions in batch modes. In this mode, the immobilized biomass was enclosed in a hanged tea bag-like cellulose membrane to facilitate the separation of the biosorbent from the treated solutions, which is one of the main challenges in applying microbial biosorption at large scale. The chemical remediation approved the potentiality to reduce nonbiodegradable components which can't be consumed by bio-remediates i.e. fungi and bacteria. Where, all the obtained biosorbent isolates showed more significant efficiency in heavy metal removal. The most potential biosorbent fungi were identified and characterized. Finally, these remediation methods can be applied for removal of different pollutants from wastewaters.
\end{abstract}

\section{INTRODUCTION}

The chemical oxidation approaches which act strongly, rapidly and are not sensitive to the type of pollutants, they can be considered as suitable alternative for bioremediation or can be used as pre or post-treatment in a sequencing system with bioremediation (Lin et al., 2004). Fenton's reagent was found to be a suitable chemical treatment method. Fenton's reagent consists of $\mathrm{H}_{2} \mathrm{O}_{2}$ and Ferrous ions 
$\left(\mathrm{Fe}^{2+}\right)$. This method has been used for wastewater treatment that contains organic pollutant (Khamaruddin et al., 2011; Burbano et al., 2008).

The idea of reaction of $\mathrm{H}_{2} \mathrm{O}_{2}$ with ferrous sulfate for decreasing of organic pollutants from wastewater samples in treatment process was as follow:

$$
\begin{aligned}
& \mathrm{H}_{2} \mathrm{O}_{2}+\mathrm{Fe}^{+2} \rightarrow \mathrm{Fe}^{+3}+\mathrm{OH}^{-}+\mathrm{OH}^{\cdot} \\
& \mathrm{Fe}^{+3}+\mathrm{H}_{2} \mathrm{O}_{2} \rightarrow \mathrm{Fe}^{+2}+\mathrm{H}^{+}+\mathrm{HO}_{2}
\end{aligned}
$$

This producing free radical has the ability to degrade the contaminant of concern. The hydroxyl radical rapidly reacts non-selectively by attacking and cleaving the carbon-hydrogen bonds of contaminant organic compounds and have been used to treat many organics such as chlorinated and non-chlorinated solvents, PAHs, esters, pesticides, VOCs, SVOCs, BTEXs, phenols and others (Amarante, 2002).

Nowadays, Physical, chemical and biological technologies are being used for reducing high concentration of metal ions from aqueous solution. Standard methods for metal ions removing from aqueous solution involve filtration, membrane technologies, chemical precipitation, chemical and electro coagulation, electrochemical treatment, ion exchange, adsorption on activated carbon, zeolite and evaporation, etc. (Ali and Gupta, 2007). Olgun and Atar (2012) stated that some wastes were found to have a significant efficiency in removing different metal ions as Lead (II) and Nickel (II). However, some processes like electrochemical treatment and chemical precipitation are ineffective, and may produce huge amount of sludge which need to be treated with great difficulty. Other processes as activated carbon adsorption process, ion exchange and membrane technologies are expensive when treating large amount of wastewater and water containing heavy metal in low concentration as a result cannot be employed at large scale (Fu and Wang, 2011).

Biosorption, a passive and metabolic independent process, could be described as heavy metals removal using a passive binding process with non-living microorganisms including algae, bacteria, filamentous fungi, and yeasts. It characterized by removal of these metals even at low concentrations from waste effluents (Parvathi and Nagendran, 2007; Vilar et al., 2007) and other biomass types that are capable of well collecting heavy metals.

The biosorption process showed many necessary characters including its rapid kinetics of adsorption and desorption, selectivity of metals at different $\mathrm{pH}$ and temperatures as well as its economic value. Bio-sorbent itself may easily be manufactured using low cost growth media or as by-product from different industries (Ahluwalia and Goyal, 2007; Ali et al., 2012).

The main advantages of biosorption over conventional treatment methods are: the efficiency to remove low pollutant concentrations, low cost, reducing use of other materials (i.e. nutrients), possibility for reuse and metal recovery (Vilar et al., 2007). These biomaterials consist of carbohydrates, proteins and phenolic compounds which have functional groups such as hydroxyls, carboxyls and amines with high binding capacity to the metal ions (Choi and Yun, 2006).

There are main numerous factors, related to the biomass and the metal or the surrounding environmental conditions, that affect biosorption process namely; $\mathrm{pH}$, temperature, the biomass nature, biomass concentration, initial concentration and metal affinity to the biosorbent (Ahalya et al., 2003; Malkoc and Nuhoglu, 2005). Different species of bacteria, yeast and filamentous fungi were proven to be a potential biosorbent and were stated to remarkably remove heavy metals from different waste effluents (Malkoc and Nuhoglu, 2005). 
Kitchener drain is one of the largest drains in Nile Delta. It lies in El-Gharbia and Kafr El-Sheikh provinces and drained into Mediterranean Sea affecting the marine environment. So this research is aimed to:

- Use one of chemical remediation methods namely; Fenton oxidation for removal of organic contaminates from wastewater.

- Using fungi as bio-remediate organisms to remove three toxic metals $(\mathrm{Cr}, \mathrm{Cd}$ and $\mathrm{Ni})$.

- These two important remediate methods can be used for keeping the marine environment from high load of organic and inorganic wastes from drainage water of Kitchener drain.

\section{MATERIALS AND METHODS}

\section{Samples collection:}

For chemical remediation process, composite sample from Kitchener drain was used, which is a mixture from the different sites distributed along this drain. While for fungal remediation experiment, four composite samples were selected from the different four sites which begin from the drainage water at Gharbia governorate and finished nearby the Mediterranean Sea (Figure 1).

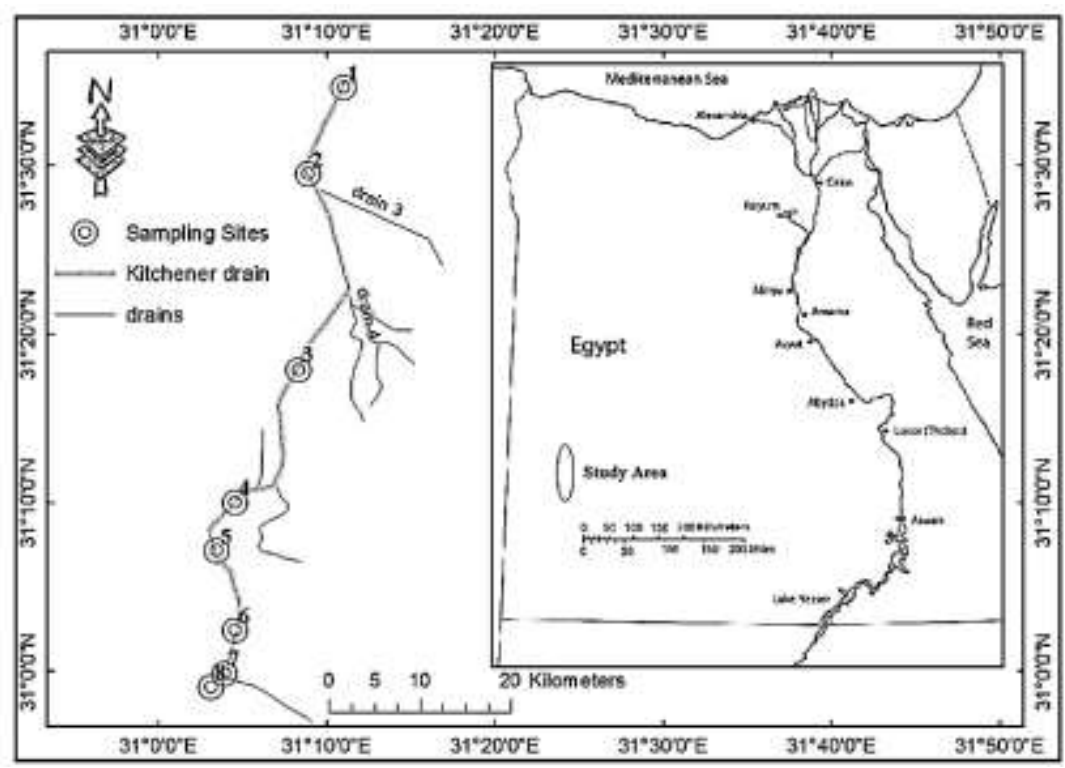

Figure 1: Map shows studied area (Kitchener drain)

\section{Chemical remediation using Fenton reagent}

According to Bham and Chambers (1997), the Fenton's reagent was prepared using hydrogen peroxide and ferrous ion salts (i.e. $\mathrm{FeSO}_{4} .7 \mathrm{H}_{2} \mathrm{O}$ ) as a highly oxidizing agent. Effect of different concentrations of hydrogen peroxide, $\mathrm{pH}$ values and at different ranges of temperature on the degradation of organic pollutants were observed by estimating COD residual.

Different concentrations of $\mathrm{FeSO}_{4}(0.1,0.2,0.4$ and $0.6 \mathrm{gm})$ were added to each 2 liters of wastewater samples in four beakers, which being described as above. Constant concentration of $\mathrm{H}_{2} \mathrm{O}_{2}$ at $20 \%$ was used and at $\mathrm{pH}$ (3) that adjusted by 0.1 $\mathrm{N}$ of hydrochloric acid $\mathrm{HCl}$ and $0.1 \mathrm{~N}$ of sodium hydroxide $\mathrm{NaOH}$. The mixtures 
were left for 3 hours at least to precipitate the ferric form producing from the reaction and the supernatant was analyzed to determine the rate of organic matter degradation.

Various concentrations from $\mathrm{H}_{2} \mathrm{O}_{2}(5,15,20$ and $30 \%)$ were prepared. Each concentration was added separately to each sample solution in the presence of 400 mg of ferrous ion salts $\left(\mathrm{FeSO}_{4}\right)$ at $\mathrm{pH} 3$. The reaction was left for 3 hours and then, residual COD was tested.

To know the effect of acidic and or alkaline medium on the reaction of Fenton reagent was estimated as five different values of $\mathrm{pH}$ were considered (2, 3, 5, 7 and 9) using $0.1 \mathrm{~N}$ of $\mathrm{NaOH}$ or $0.1 \mathrm{~N} \mathrm{HCl}$ in the presence of $20 \mathrm{~mL}$ of hydrogen peroxide $15 \%$ and $400 \mathrm{mg}$ of ferrous ion salts $\left(\mathrm{FeSO}_{4}\right)$ as optimal values. After 3 hours, the residual COD were determined

Also, different ranges of temperature $\left(10,20,30,40\right.$ and $\left.50^{\circ} \mathrm{C}\right)$ were used with the optimal values of ferrous sulfate, hydrogen peroxide and $\mathrm{pH}$ which are 0.4 gm, $15 \%$ and 2 for each, respectively. After 3 hours the residual COD were determined.

\section{Chemical Oxygen Demand (COD)}

COD was determined using the dichromate reflux method accordin to APHA (1998). Where the amount of oxidizable organic matter, measured as oxygen equivalent, is proportional to potassium dichromate consumed and titrated against ferrous ammonium sulfate (FAS) as a the following equation:

$\operatorname{CoD}(\mathrm{mg} \mathrm{O} 2 / L)=\frac{(A-B) * N * 8000}{m l \text { sample }}$

Where A: ml used of FAS for blank, B: ml used of FAS for Sample, N: normality of FAS and 8000: milli-equivalent weight of $\mathrm{O}_{2} * 1000 \mathrm{ml} / 1$.

\section{Fungal remediation methods}

\section{Isolation of the resistant fungi}

For isolating the resistant fungi from the collected samples; one $\mathrm{ml}$ of each collected water samples was added to a Potato Dextrose agar PDA medium. These media were amended with $50 \mathrm{ppm}$ of $\mathrm{Cr}^{+6}, 50 \mathrm{ppm}$ of $\mathrm{Cd}^{+2}$ and $50 \mathrm{ppm}$ of $\mathrm{Ni}^{+2}$ separately. The inoculated fungal plates were incubated at $28^{\circ} \mathrm{C}$ for 7 days. The fungal colonies were collected, sub-cultured, purified and were preserved on PDA slants for further work.

\section{Determination of minimum inhibitory concentrations (MICs)}

The resistance of the selected isolates to $\mathrm{Cr}^{6+} \mathrm{Cd}^{2+}$ and $\mathrm{Ni}^{+2}$ was determined by the dilution method. Metal ions were added separately to PDA medium at concentrations of $50 \mathrm{ppm}$ to $1000 \mathrm{ppm}$, the plates were inoculated with $8 \mathrm{~mm}$ agar plugs from young fungal colonies, pre-grown on PDA. Three replicates of controls without metal and each concentration were used. The inoculated plates were incubated at $28^{\circ} \mathrm{C}$ for 7 days. The MIC is defined as the lowest concentration of metal that inhibit visible growth of the isolate (Ezzouhri et al., 2009).

\section{Screening for the most potential biosorbent fungi}

Eight different fungal isolates were screened for their capability to be used as a possible biosorbent for removal of cadmium, chromium and nickel from wastewater samples. They were found to have a relatively high resistant against high concentrations of the tested metals at the preliminary MIC experiments.

Regarding the resistant fungi, the tested fungal isolates were grown on solid media and a spore suspension for each was prepared and immobilized using alginate beads. The beads containing the proposed biomass were pretreated with $0.1 \mathrm{M} \mathrm{HCl}$. 
Afterwards, the pretreated beads containing fungal spore suspension were placed in cellulose tissue that was enveloped into a "tea-bag"-like shape $(4 \times 4 \mathrm{~cm})$. The tea-bag containing the beads was fixed into the middle of $250 \mathrm{ml}$ glass beaker flask containing solution of heavy metal content as shown in Figure 2.

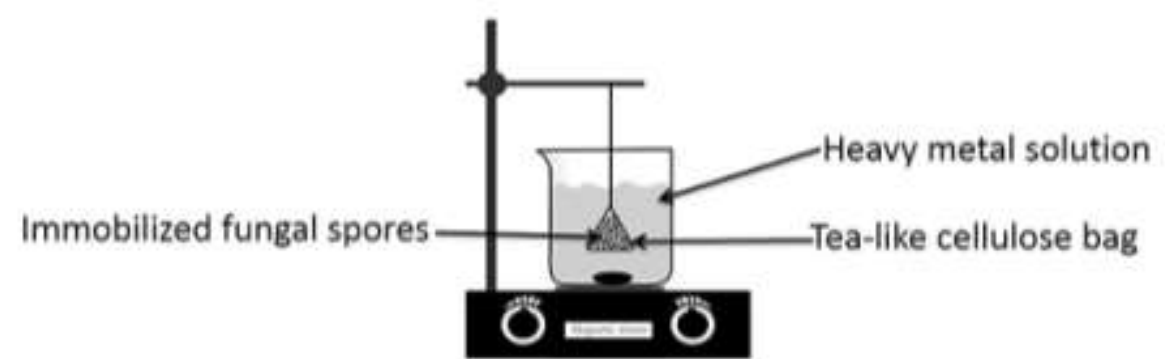

Fig. 2: The system for screening the most potential biosorpent fungal biomass for heavy metals removal in a batch mode (Migahed et al., 2016).

A dummy variable (empty alginate beads) was used to assess the standard error of the design and as a blank to confirm that the biosorption capability was related to the biomass within the beads.

The screening experiments were implemented with a prepared solution in $\mathrm{mg} / \mathrm{l}$ as an initial concentration of heavy metal. The immobilized most potential biosorbent fungal biomass were immersed in this solution (batch mode) as shown in Figure 2 and the remaining heavy metal concentrations were measured (via atomic absorption technique) and heavy metal removal were calculated as a percentage.

Identification of the most potential fungal isolates:

The most important fungal isolates that were described to be capable to remove heavy metal from the standard aqueous solutions were identified as follow;

\section{Morphologically}

Potato Dextrose Agar (PDA) was used for culturing fungi. Isolated fungi were identified based on the cultural and morphological characteristics observations, colony color and sporulation. Examination was carried out using needle-mount preparation whereby fragments of the sporing surface of the culture was taken. This was teased out in drop of alcohol on a cleaned glass slide using needle. The piece was stained by adding a drop of lactophenol. A cover slip was applied carefully avoiding air bubbles and the preparation was examined under light microscope (Barnett and Hunter, 1999).

\section{Molecularly}

The fungal DNA was extracted by employing the FastDNA® Spin Kit according to the supplier's instructions. The yield of genomic DNA was measured by a Nano Drop spectrophotometer by measuring the absorbance at $260 \mathrm{~nm}$. The ITS1 region from DNA sample extracts was amplified in triplicate using universal primers with high specificity for fungi 18FITS1 (5'-CTTGGTCATTTAGAGGAAGTAA-3') and 18RITS4 (5'- TCCTCCGCTTATTGATATGC-3'). The PCR reaction was prepared as followed: $5 \mu 1$ master mix, $20 \mu 1$ each of primers ITS1 and ITS4, $3 \mu 1$ of $50 \mathrm{mM} \mathrm{MgCl} 2,0.5 \mu 1$ of AmpliTaq DNA polymerase, and $1 \mu \mathrm{l}$ of genomic DNA and the total volume was made up with distilled water to $50 \mu \mathrm{l}$. The PCR reactions were performed in a thermo-cycler using the temperature programs: $94{ }^{\circ} \mathrm{C}$ for $5 \mathrm{~min}, 94{ }^{\circ} \mathrm{C}$ for $40 \mathrm{~s}, 55^{\circ} \mathrm{C}$ for $45 \mathrm{~s}, 72{ }^{\circ} \mathrm{C}$ for $1.5 \mathrm{~min}, 72{ }^{\circ} \mathrm{C}$ for $7 \mathrm{~min}(35$ cycles $)$. The sizes of the PCR products were determined by electrophoresis on $1.5 \%$ agarose gels $(1.5 \%$ $\mathrm{w} / \mathrm{v} ; 30 \mathrm{~min}$ at $100 \mathrm{~V}, 1 \mathrm{X} \mathrm{TBE})$. The amplified fragments were compared with 100 
bp molecular size marker (MBI Fermentas, Lithuania). The desired products were excised and purified by the Qiagen II Agarose Gel Extraction Kit according to the supplier's instructions. The PCR product was stored at $-20^{\circ} \mathrm{C}$.

The sequencing reactions were performed in a thermocycler (Master cycler, Eppendorf, Hamburg, Germany) at a total volume of $10 \mu \mathrm{l}$ by using the temperature program: $96{ }^{\circ} \mathrm{C}$ for $1 \mathrm{~min}, 96^{\circ} \mathrm{C}$ for $30 \mathrm{~s}, 60{ }^{\circ} \mathrm{C}$ for $10 \mathrm{~s}, 60^{\circ} \mathrm{C}$ for $4 \mathrm{~min}, 72^{\circ} \mathrm{C}$ for 5 min ( 25 cycles).

The sequencing reaction products were purified by employing the Dye Ex 2.0 Spin Kit according to the supplier's instructions. The purified sequencing reaction products were dried in vacuum centrifuge and then analyzed using applied biosystems (ABI PRISM Big Dye Terminator v1.1), Ready Reaction Cycle Sequencing Kit and employing an ABI 3130 XL Genetic Analyzer (Applied Biosystems, Darmstadt) (Mullis 1990). The obtained sequences were annotated using the Sequencher TM 4.8 Software. DNA similarity searches were performed using the BlastN program and the databases of European Molecular Biology Laboratory (EMBL) and GenBank from the National Center for Biotechnology Information website (NCBI).

The phylogenetic and molecular evolutionary analyses for 18S rRNA gene nucleotide sequences were conducted for sequence alignments using the computer programs ClustalW and BioEdit 7.0.5.3 and implement in MEGA software version 6.

The phylogenetic trees were constructed using the Neighbor-Joining (Muzyka et al., 2014) algorithm method. Distances were generated using the Kimura Matrix, and the tree stability was supported through Bootstrap analysis (1000 replications).

\section{Analytically}

\section{Preparation of Fatty Acid Methyl Esters (FAMEs)}

For the saponification of the fungal fatty acids $40 \mathrm{mg}$ cells were resuspended in $1 \mathrm{ml}$ of solution 1 (Methanol and $15 \% \mathrm{NaOH}(\mathrm{w} / \mathrm{v})$ ) in a $4 \mathrm{ml}$ glass vial and securely sealed with a Teflon lined cap. The suspension was boiled for $1 \mathrm{~h}$ at $100^{\circ} \mathrm{C}$ in a heating block. Then the solution was cooled to room temperature.

To methylate the saponified fatty acids $1.8 \mathrm{ml}$ of solution 2 (Methanol and 37\% $\mathrm{HCl}$ ) was added followed by another heating step at $80^{\circ} \mathrm{C}$ for $10 \mathrm{~min}$. The reaction was quickly stored on ice until cooled. For the extraction of the fatty acid methyl esters (FAMEs) from the aqueous phase, $0.9 \mathrm{ml}$ of solution 3 (Hexane and Tetrabutyl ethyl ether) was added. After vigorous vortexing for 30 seconds, the upper organic phase was transferred to a new $4 \mathrm{ml}$ vial. This extraction step was performed three times. To prevent contamination from the organic phase during gas chromatography analysis, $3 \mathrm{ml}$ of basic solution $4(0.5 \mathrm{M} \mathrm{NaOH})$ were added. After vortexing again for 30 seconds the organic phase was transferred to a $2 \mathrm{ml} \mathrm{crimp}$ top vial. The solvent was evaporated by a gentle stream of nitrogen. For the gas chromatographic analysis FAMEs were resuspended in n-octane containing internal standard n-alkanes $\mathrm{C}_{24} \mathrm{H}_{50}$ and $\mathrm{C}_{16} \mathrm{H}_{34}$.

\section{Gas Chromatography (GC)}

The extracted FAMEs were analysed by employing an Agilent $6890 \mathrm{~N}$ gas chromatograph equipped with a 5\% -Phenyl Methylpolysiloxan Optima 5 capillary column (50 m length; $0.32 \mathrm{~mm}$ inner diameter; $0.25 \mu \mathrm{m}$ film thickness and a Flame Ionisation Detector (FID). Hydrogen served as the carrier gas. For FAMEs analysis the injector temperature was set to $250^{\circ} \mathrm{C}$ and the detector temperature was $300^{\circ} \mathrm{C}$. The oven program for the FAMEs analysis was $100^{\circ} \mathrm{C}$ for 2 minutes, subsequently increasing the temperature to $290^{\circ} \mathrm{C}$ at $4{ }^{\circ} \mathrm{C} \mathrm{min}^{-1}$. The heating steps are followed by an isothermal period of 10 minutes. 


\section{RESULTS AND DISCUSSION}

\section{Chemical remediation using Fenton reagent Effect of ferrous sulfate dosage}

Fenton's oxidation, advanced oxidation catalyzed with ferrous iron $\left[\mathrm{Fe}^{+2}\right]$, is successful in removing organics from water (Bergendahl et al., 2003). The ratio of $\mathrm{H}_{2} \mathrm{O}_{2} / \mathrm{Fe}^{+2}$ is an important determinant in the efficiency of Fenton oxidation (Mang et al., 2010). According to Abd El-Hamid (2015), the removal of organic matter as COD concentration is at $20 \% \mathrm{H}_{2} \mathrm{O}_{2}$ and $\mathrm{pH}=3$. For wastewater from Kitchener drain in this study, the optimum concentration of iron catalyst is very important, so different concentrations from $\mathrm{Fe}^{+2}$ in the phase of $\mathrm{FeSO}_{4} \cdot 7 \mathrm{H}_{2} \mathrm{O}$, which is efficient as a coagulant aid, was used $(0.1,0.2,0.4$ and $0.6 \mathrm{gm})$. The high COD removal was obtained at $0.4 \mathrm{gm}$ of ferrous sulfate (Figure 3a). Also, to enable an optimal production of radicals by reaction between $\mathrm{Fe}^{2+}$ and $\mathrm{H}_{2} \mathrm{O}_{2}$, the presence of oxygen should be prevented in order to prevent formation of iron hydr-oxides, which take away the iron from the catalytic cycle. Thus, anaerobic water conditions are required (Ijpelaar et al., 2001).

\section{Effect of hydrogen peroxide dosage}

The agent used for Fenton process is mainly hydrogen peroxide $\left(\mathrm{H}_{2} \mathrm{O}_{2}\right)$. Hydrogen peroxide $\left(\mathrm{H}_{2} \mathrm{O}_{2}\right)$ is a strong oxidant and its application in the treatment of various inorganic and organic pollutants is well established.

Usually it had been observed that the percentage degradation of the organic wastes increased with an increase in the dosage of hydrogen peroxide (Kang and Hwang, 2000). It was known that the presence of excess hydrogen peroxide was harmful to many of the organisms (Ito et al., 1998). High dosage of $\mathrm{H}_{2} \mathrm{O}_{2}$ is a remarkable source for $\mathrm{OH}$. Production, and Tang and Huang (1996) recommended that usage of moderate volume of hydrogen peroxide is suggested in Fenton reaction. In this search, different concentrations of $\mathrm{H}_{2} \mathrm{O}_{2}$ were used $(5,10,15$ and $20 \%)$. This is observed that the maximum COD removal occurs at optimal concentration of $15 \%$ $\mathrm{H}_{2} \mathrm{O}_{2}$ (Figure 3b). It's obvious that more addition of $\mathrm{H}_{2} \mathrm{O}_{2}$, the efficiency of removal is declined. For this ratio the percent of removal is $80 \%$, and changed to $60 \%$ at $20 \%$ $\mathrm{H}_{2} \mathrm{O}_{2}$. The minimum removal of COD at $5 \% \mathrm{H}_{2} \mathrm{O}_{2}$. Abd El-Hamid (2015) found the same results in removal of hydrocarbon wastes from water samples.

By the dissociation into oxygen and water, $\mathrm{H}_{2} \mathrm{O}_{2}$ can also supply oxygen for microorganism in biological treatment facilities and in bioremediation of contaminated sites.

\section{Effect of pH concentration}

Different values of $\mathrm{pH}$ were used in the process of Fenton for optimum conditions to degrade the contaminants of wastewater. As Figure (3c), the optimum $\mathrm{pH}$ was at the acidic medium $(\mathrm{pH}=2)$. As Ertugay and Acar (2013) showed the reaction rates of Fenton oxidation were rather slow in alkaline medium and were fast in acidic medium. (Khamaruddin et al., 2011) find that the best $\mathrm{pH}$ for treatment was 2.5. (Chu et al., 2012) observed that the oxidation potential of hydroxyl radicals decreased with increasing $\mathrm{pH}$. Fenton's reagent is more rapid and efficient under low $\mathrm{pH}$ conditions ( $\mathrm{pH} 2$ to 4 is optimal).

\section{Effect of temperature range}

The range of temperature affects the limit of reaction of Fenton reagent. The used values were at $10,20,30,40$ and $50^{\circ} \mathrm{C}$. The optimum value of temperature is at $40^{\circ} \mathrm{C}$ (Figure 3d). This result is agreed with Lucas and Peres (2009) who found that 
the optimal temperature is found between 30 to $40^{\circ} \mathrm{C}$, while reaction is constant between 20 to $30{ }^{\circ} \mathrm{C}$. Increasing the temperature had two opposite effects on the reaction yield. Most probably the generation rate of $\mathrm{OH}^{*}$ is enhanced at a high temperature but when the temperature approaches $60^{\circ} \mathrm{C}$, hydrogen peroxide undergoes self-accelerating decomposition and there was almost no change in COD removal efficiency above $40^{\circ} \mathrm{C}$ (Gulkaya et al., 2006).

From the previous results, using mixing process during the reaction of Fenton reagent aid in the removal of nearly $80-96 \%$ of COD from contaminated samples. After the Fenton's reagent has been completely depleted, the breakdown products of the spent hydrogen peroxide can serve as an oxygen source for microbes to enhance biodegradation of contaminants.
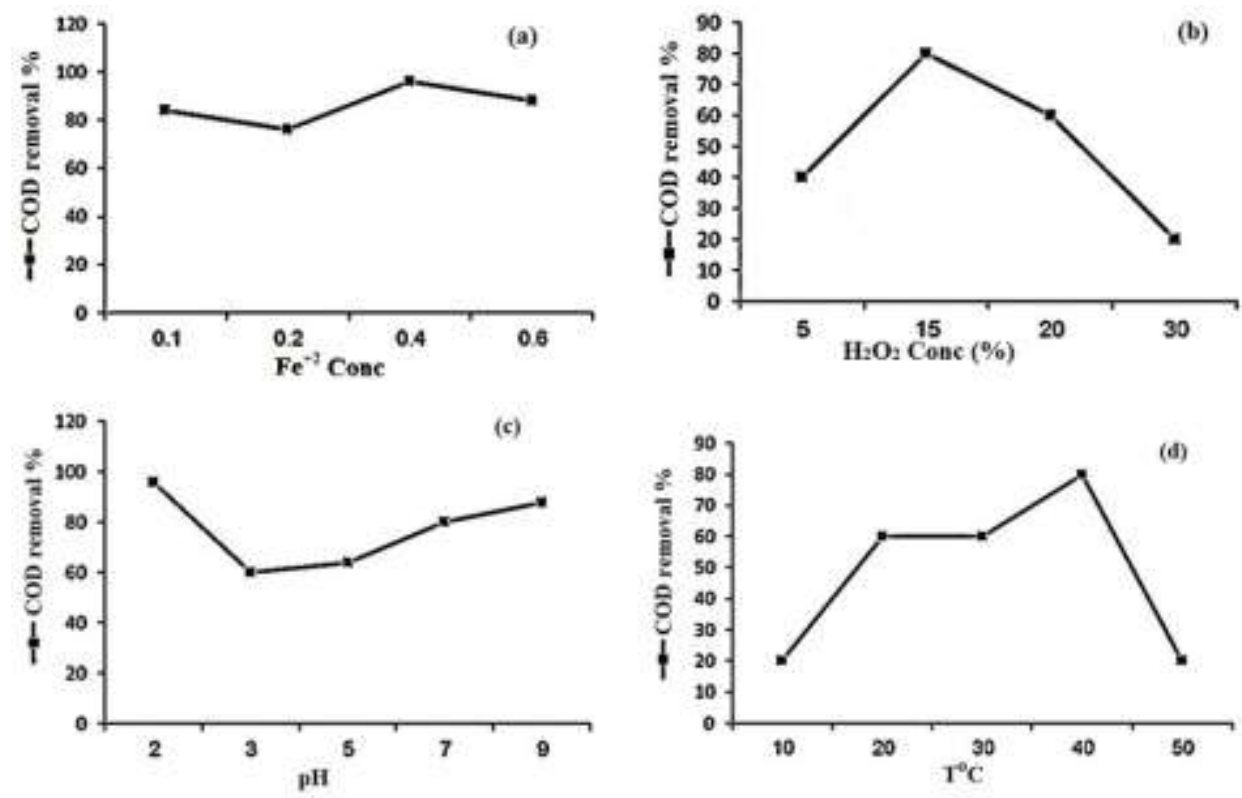

Fig. 3: The optimum values for different variables in Fenton process; (a) $\mathrm{Fe}^{+2}$, (b) $\mathrm{H}_{2} \mathrm{O}_{2}$, (c) $\mathrm{pH}$ and (d) $\mathrm{T}^{\circ} \mathrm{C}$.

\section{Isolation of the heavy metal resistant microbes}

Twenty fungal strains were isolated, from the collected wastewater samples, on PDA media containing $50 \mathrm{ppm}$ of $\mathrm{Cr}, \mathrm{Cd}$ and $\mathrm{Ni}$ separately to confirm the preselection of potential heavy metal resistant isolates. The microbial mixtures were prepared and applied in a batch mode to examine the efficiency of the tested microbial mixtures to remove $\mathrm{Cr}, \mathrm{Cd}$ and $\mathrm{Ni}$ from the prepared solution. The rate of targeted ions removal in each trial was calculated and used as a response to be analyzed and maximizing the rate capability of removal as aim (Table 1).

Eight different isolated microbes were used to perform such experiment. They were selected due to their capability to grow and resist relatively high concentrations of the targeted heavy metals during the preliminary MIC experiments when amended to the cultivation media. The used biomass was pretreated fungal spores by soaking in a light acidic solution which leads to improve the biosorption proficiency and remove any by-products which may pose a hazard to the environment (Aqeel Ashraf et al., 2012). Empty alginate beads were used to evaluate the design's standard error and as a blank to confirm the relation between biosorption capabilities to the biomass within the beads.

The heavy metal removal percentages were calculated as defined in the following equation: 
Biosorption removal Rate $\%=\frac{C_{f}-C_{i}}{C_{f}} * 100$

Where $\mathrm{C}_{i}(\mathrm{ppm})$ is the initial concentration of metal ion, $\mathrm{C}_{f}(\mathrm{ppm})$ is the metal ion concentration after biosorption. All biosorption experiments were repeated three times to confirm the results. Also, blank experiments were tested to ensure that no adsorption had occurred on the apparatus walls.

Table 1: The biosorption capability of the isolated microbial strains.

\begin{tabular}{|c|c|c|c|c|c|c|c|c|c|}
\hline \multirow{3}{*}{ Site } & \multicolumn{9}{|c|}{ The concentrations of heavy metals in water of Kitchener drainage $(\mu \mathrm{g} / \mathrm{ml})$} \\
\hline & \multicolumn{3}{|c|}{$\mathrm{Cd}$} & \multicolumn{3}{|c|}{$\mathrm{Cr}$} & \multicolumn{3}{|c|}{$\mathrm{Ni}$} \\
\hline & $\mathrm{C}_{i}$ & $\mathrm{C}_{f}$ & $\begin{array}{c}\text { removal } \\
\text { rate }\end{array}$ & $\mathrm{C}_{i}$ & $\mathrm{C}_{f}$ & $\begin{array}{c}\text { removal } \\
\text { rate }\end{array}$ & $\mathrm{C}_{i}$ & $\mathrm{C}_{f}$ & $\begin{array}{c}\text { removal } \\
\text { rate }\end{array}$ \\
\hline 1 & 27.37 & 4.32 & 84.2 & 37.23 & 18.76 & 49.6 & 42.12 & 13.73 & 67.4 \\
\hline 2 & 3.30 & 0.28 & 91.5 & 2.48 & 1.05 & 57.5 & 2.31 & 0.55 & 76.3 \\
\hline 3 & 9.64 & 2.01 & 79.2 & 9.96 & 5.27 & 47.1 & 13.55 & 4.07 & 70.0 \\
\hline 4 & 11.51 & 2.81 & 75.6 & 13.57 & 5.89 & 56.6 & 19.94 & 7.48 & 62.5 \\
\hline
\end{tabular}

Abbreviation: $\mathrm{C}_{i}$ : initial concentration of metal ion, $\mathrm{C}_{f}$ : final concentration of metal ion after biosorption

\section{Phylogeny of the most potential biosorbent fungi}

The 18S ribosomal RNA gene was used as an eukaryotic marker for fungi. The sequence analysis of the $18 \mathrm{~S}$ ribosomal RNA was compared to the database at NCBI. The genera Dichotomomyces, Gymnascella, Mortierella, Penicillium, Pseudallescheria, Talaromyces, and Zopfiella were found in the Kitchener sites (Table 2). The phylogenetic tree depicted the classes of theses fungal strains. The fungal strains were members of Eurotiomycetes, Sordariomycetes and Zygomycetes (Fig. 4).

Table 2: Sequence homology of the 18S rRNA gene of the most potential biosorbent fungal isolates from the Kitchener sites

\begin{tabular}{|c|c|c|l|c|}
\hline Site & Isolate & Size (bp) & Closely related fungi with accession number & Homology (\%) \\
\hline \multirow{2}{*}{ S1 } & Isolate1 & 569 & Zopfiella latipes FJ175158 & 96 \\
\cline { 2 - 5 } & Isolate2 & 592 & Penicillium griseofulvum GQ305305 & 97 \\
\hline \multirow{2}{*}{ S2 } & Isolate1 & 724 & Mortierella sp. AJ541798 & 96 \\
\cline { 2 - 5 } & Isolate2 & 1045 & Talaromyces trachyspermus EU076917 & 99 \\
\hline \multirow{2}{*}{ S3 } & Isolate1 & 520 & Dichotomomyces cejpii EF669956 & 96 \\
\cline { 2 - 5 } & Isolate2 & 501 & Pseudallescheria boydii FJ713064 & 90 \\
\hline \multirow{2}{*}{ S4 } & Isolate1 & 549 & Gymnascella hyalinospora AF129853 & 98 \\
\cline { 2 - 5 } & Isolate2 & 533 & Pseudallescheria boydii EU332872 & 100 \\
\hline
\end{tabular}

\section{Analysis of fatty acids of the most potential biosorbent fungal isolates}

From Fig. 5 and Table 3, it was found that the major cellular fatty acids in the most potential biosorbent fungal isolates from the Kitchener sites that were able to remove heavy metals $(\mathrm{Cr}, \mathrm{Cd}$ and $\mathrm{Ni}$ ) were $\mathrm{C} 16: 0, \mathrm{C} 17: 0, \mathrm{C} 18: 0, \mathrm{C} 19: 0, \mathrm{C} 16: 1 \omega 7$, $\mathrm{C} 18: 2 \omega 6,9$, and $\mathrm{C} 18: 1 \omega 9$. 


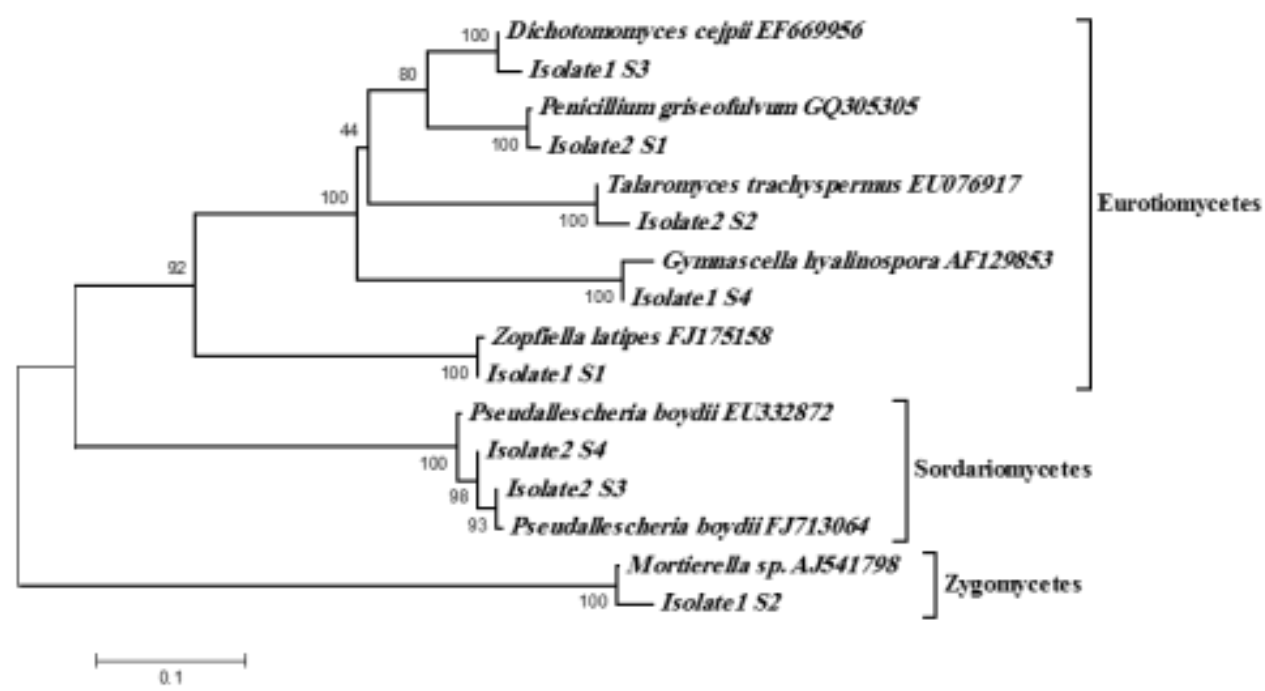

Fig. 4: Phylogeny of the most potential biosorbent fungal isolates from the Kitchener sites that were able to remove heavy metals $(\mathrm{Cr}, \mathrm{Cd}$ and $\mathrm{Ni}$ ). Multiple alignments of the sequences corresponding to the $18 \mathrm{~S}$ rRNA of the studied isolates were carried out followed by neighbor joining clustering. Bootstrap values expressed as percentages of 1000 replications. Bar represents 0.1 substitutions per nucleotide position.

Table 3: Major cellular fatty acids content (\%) of the most potential biosorbent fungal isolates. Values are percentage of total fatty acids and (-) not detected.

\begin{tabular}{|c|c|c|c|c|c|c|c|c|}
\hline \multirow{2}{*}{ Fatty acid } & \multicolumn{2}{|c|}{ S1 } & \multicolumn{2}{c|}{ S2 } & \multicolumn{2}{c|}{ S3 } & \multicolumn{2}{c|}{ S4 } \\
\cline { 2 - 9 } & Isolate1 & Isolate2 & Isolate1 & Isolate2 & Isolate1 & Isolate2 & Isolate1 & Isolate2 \\
\hline C16:0 & 24.3 & 19.4 & 18.5 & 19.1 & 22.2 & 18.9 & 28.7 & 18.9 \\
\hline $\mathrm{C} 17: 0$ & - & - & - & 1.5 & - & - & - & - \\
\hline $\mathrm{C} 18: 0$ & - & 2.9 & - & 4.4 & - & 1.5 & 4.4 & 1.5 \\
\hline $\mathrm{C} 19: 0$ & 4.3 & - & 8.2 & - & 4.9 & 2.9 & - & 2.9 \\
\hline $\mathrm{C} 16: 1 \omega 7$ & - & 1.3 & - & - & - & 1.1 & - & 1.1 \\
\hline $\mathrm{C} 18: 2 \omega 6,9$ & 50.9 & 45.7 & 36.2 & 48.8 & 59.2 & 48 & 39.6 & 48 \\
\hline $\mathrm{C} 18: 1 \omega 9$ & 24.6 & 30.7 & 37.1 & 26.1 & 13.7 & 29 & 27.2 & 29 \\
\hline
\end{tabular}

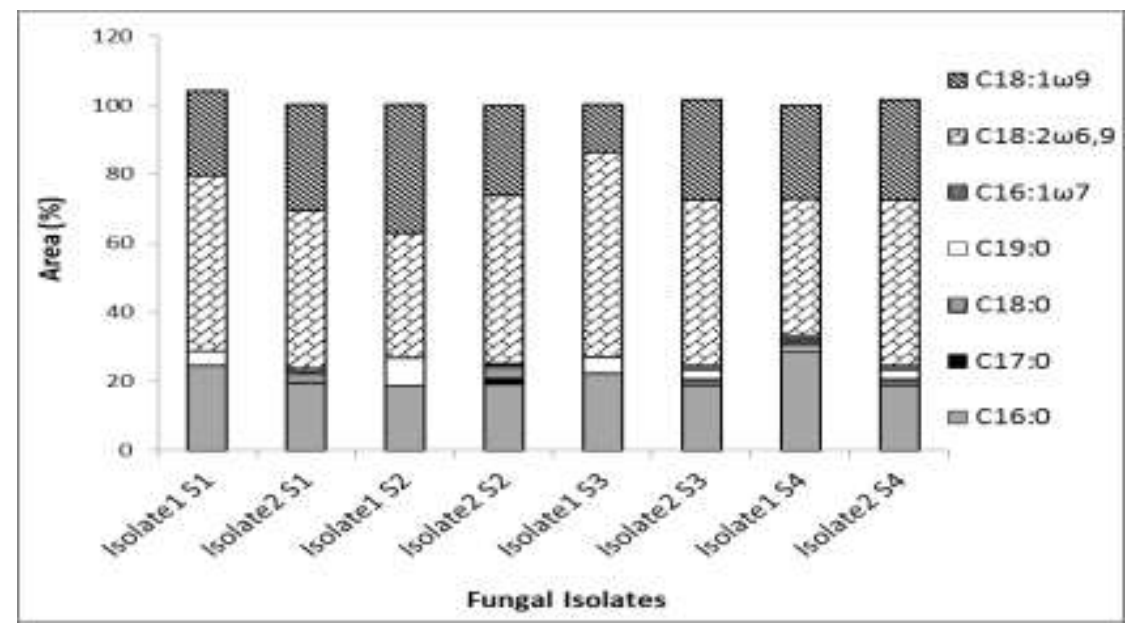

Fig. 5: Percentage of the extracted fatty acids from the most potential biosorbent fungal isolates.

\section{CONCLUSION}

It's concluded that Fenton reagent is an effective chemical treatment method as it can remove more than $90 \%$ of organic matter estimated as COD. Optimization of the Fenton reaction conditions as $\mathrm{pH}, \mathrm{T}^{\circ} \mathrm{C}$, dosage of $\mathrm{H}_{2} \mathrm{O}_{2} / \mathrm{Fe}^{+2}$ is important to have high removal percentage. The study is agreed with other studies that Fenton is more 
effective in acidic medium at $40^{\circ} \mathrm{C}$. And the study recommended using Fenton reagent with wastewaters in an aerobic condition.

Heavy metals were listed be a severe problem due to its risk on human health. Biosorption was described to be a potential approach for toxic heavy metals removal or reducing to its minimum acceptable limits. Microbial biomass was reported to successfully remove some heavy metals in batch modes (Colak et al., 2013).

In this research, a batch mode was developed, to screen the efficiency of a great number of fungal strains, isolated from the Kitchener drain, to remove Chromium, Cadmium and Nickel ions. Immobilizing the immobilized biomass in a tea bag-like membrane is expected solve one of the main problems in microbial biomass applications where the used biosorbent removal and its separation from the treated solution will be easier and efficient. Eight fungal isolates were identified to be a potential consortium to remove heavy metals from Kitchener drain, as this generated consortium was effecien in removing most of the Cadmium and Nickel ions and more than half of the Chromium ions from both the prepared standard solutions and the real Kitchener drain even in the presence of heavy metals. The genera Dichotomomyces, Gymnascella, Mortierella, Penicillium, Pseudallescheria, Talaromyces, and Zopfiella were found in the Kitchener sites. The fungal strains were members of Eurotiomycetes, Sordariomycetes and Zygomycetes. The generated consortium achieved the desired target when introduced in batch mode.

For the future work, the generated consortium will be introduced in continuous modes to achieve the desired target and the action mechanism of this consortium will be studied and explained which could be challenging.

\section{REFERENCES}

Abd El-Hamid, H.T. 2015. Detection and remediation of hydrocarbon wastes along the coastline from Damietta to Port Said. . PhD, Environmental Sciences Department, Faculty of Science, Damietta University. .

Ahalya, N.; Ramachandra, T. and Kanamadi, R. 2003. Biosorption of heavy metals. Res. J. Chem. Environ., 7:71-79.

Ahluwalia, S.S and Goyal, D. 2007. Microbial and plant derived biomass for removal of heavy metals from wastewater. Bioresour Technol, 98:2243-2257.

Ali, I.; Asim, M. and Khan, T.A. 2012. Low cost adsorbents for the removal of organic pollutants from wastewater. J. Environ. Manag., 113:170-183.

Ali, I. and Gupta, V. 2007. Advances in water treatment by adsorption technology. Nat Protoc, 1:2661-2667.

Amarante, D. 2002. Applying In Situ Chemical Oxidation. Pollu Eng, 40-42.

APHA, 1998. Standard methods for the examination of water and waste water, 19th Edition. American Public Health Association, American Water Work Association, Water Pollution Control Federation, Washington, D.C.

Aqeel Ashraf, M.; Maah, J. and Yusoff, I. 2012. Removal of lead from synthetic solutions by protonated teleosts biomass. J. Chem., 9:345-353.

Barnett, H.L. and Hunter, B.B. 1999. Illustrated genera of imperfect fungi.4th edition, 2nd printing, APs Press, the American phytopatholocal society, St. Paul, Minnesota.218.

Bergendahl, J.; Hubbard, S. and Grasso, D. 2003. Pilot-scale Fenton's oxidation of organic contaminants in groundwater using autochthonous iron. J Haz Mat, 99:43-56. 
Bham, A.A. and Chambers, R.P. 1997. Degradation of high molecular weight chlorinated aromatics and aliphatics in bleach plant effluent by Fenton's Reagent. Adv in Enviro Res, 1:135-143.

Burbano, A.A.; Dionysiou, D.D. and Suidan, M.T. 2008. Effect of oxidant-tosubstrate ratios on the degradation of MTBE with Fenton reagent. Wat Res, 42 (12):3225-3239.

Colak, F.; Olgun, A.; Atar, N. and Yazıcıog lu, D. 2013. Heavy metal resistances and biosorptive behaviors of Paenibacillus polymyxa: batch and column studies. J Ind Eng Chem, 19(3):863-869.

Choi, S.B. and Yun, Y.S. 2006. Biosorption of cadmium by various types of dried sludge: an equilibrium study and investigation of mechanisms. J Haz Mat, 138:378-383.

Chu, L.; Wang, J.; Dong, J.; Liu, H. and Sun, X. 2012. Treatment of coking wastewater by an advanced Fenton oxidation process using iron powder and hydrogen peroxide. Chemo, 86 (4):409-414.

Ertugay, N. and Acar, F.N. 2013. Removal of COD and color from Direct Blue 71 azo dye wastewater by Fenton's oxidation: Kinetic study. Arab J Chem, http://dx.doi.org/10.1016/j.arabjc.2013.02.009.

Ezzouhri, L.; Castro, E.; Moya, M.; Espinola, F. and Lairini, K. 2009. Heavy metal tolerance of filamentous fungi isolated from polluted sites in Tangier, Morocco. Afr J Micro Res, 3 (2):35-48.

Fu, F. and Wang, Q. 2011. Removal of heavy metal ions from wastewaters: a review. J Environ Manag, 92:407-418.

Gulkaya, I.; Surucu, G.A. and Dilek. F.B. 2006. Importance of H2O2/Fe2+ ratio in Fenton's treatment of a carpet dyeing wastewater. J Haz Mat, 136 (3):763-769.

Ijpelaar, G.F.; Groenendijk, M.; Kruithof, J.C. and Schippers. J.C. 2001. Fenton process for combined removal of iron and organic micropollutants in groundwater treatment. IWA World water congress, Berlin, 15-19 october 2001.

Ito, K.; Jian, Nishijima, W.W.; Baes, A.U. and Shoto, E. 1998. Comparison of ozonation and AOPs combined with biodegradation for removal of THM precursors in treated sewage effluents. J Wat Sci Tech, 38:179-186.

Kang, Y.W. and Hwang, K.Y. 2000. Effects of reaction conditions on the oxidation efficiency in the Fenton process. Wat Res, 34:2786-2790.

Khamaruddin, P.F.; Bustam, M.A. and Omar, A.A. 2011. Using Fenton's Reagents for the degradation of Diisopropanolamine: Effect of Temperature and $\mathrm{pH}$. Paper presented at the International Conference on Environment and Industrial Innovation, Singapore.

Lin, Q., C. Yingxu, W.Z.; and Wang. Y. 2004. Study on the possibility of hydrogen peroxide pretreatment and plant system to remediate soil pollution. Chemo, 57:1439-1447.

Lucas, M.S. and Peres, J.A. 2009. Removal of COD from olive mill wastewater by Fenton's reagent: Kinetic study. J Haz Mat, 168 (2-3):1253-1259.

Malkoc, E. and Nuhoglu, Y. 2005. Investigations of nickel(II) removal from aqueous solutions using tea factory waste. J Haz Mat, 127:120-128.

Mang, L.; Zhongzhi, Z.; Wei, Q.X.W.; Yueming, G.; Qingxia, M. and Yingchun. G. 2010. Remediation of petroleum contaminated soil after composting by sequential treatment with Fenton-like oxidation and biodegradation. Biores Techn, 101:2106-2113. 
Migahed, F.; Abdelrazak, A. and Fawzy, G. 2016. Batch and continuous removal of heavy metals from industrial effluents using microbial consortia. Int $\mathbf{J}$ Environ Sci Techn, 14 (6):1169-1180.

Mullis, K.B. 1990. The unusual origin of the polymerase chain reaction. Sci Am, 262 (4):56-61.

Muzyka, D.; Pantin-Jackwood, M.; Stegniy, B.; Rula, O.; Bolotin, V. and Stegniy, A. 2014. Wild bird surveillance for avian paramyxoviruses in the Azov-black sea region of Ukraine (2006 to 2011) reveals epidemiological connections with Europe and Africa. Appl Environ Microbiol, 80 (17):5427-5438.

Olgun, A. and Atar, N. 2012. Equilibrium, thermodynamic and kinetic studies for the adsorption of lead(II) and nickel(II) onto clay mixture containing boron impurity. J Ind Eng Chem, 18 (5):1751-1757.

Parvathi, K. and Nagendran. R. 2007. Biosorption of chromium from effluent generated in chrome-electroplating unit using Saccharomyces cerevisiae. Sep Sci Technol, 42:625-638.

Tang, W.Z.; and Huang. C.P. 1996. 2,4-Dichlorophenol Oxidation Kinetics by Fenton's Reagent. Environ.Technol, 17:1371-1378.

Vilar, V.J.; Botelho, C.M. and Boaventura, R.A. 2007. Modeling equilibrium and kinetics of metal uptake by algal biomass in continuous stirred and packed bed adsorbers. Adsorp, 13:587-601. 